\title{
Tackling Human Trafficking \\ Importance of Counter Trafficking in International \\ Development: Sharing IOM's Best Practices
}

International Organization for Migration(IOM)

\section{Contents}

I. Human Trafficking - A Global Phenomenon

1. Definition of Trafficking in Persons

II. Types of Human Trafficking or Forms of Exploitation

1. Human Trafficking for the purpose of sexual exploitation

2. Human trafficking for the purpose of labour exploitation

3. Child trafficking: Children as a special case

III. Causes of Human Trafficking

IV. The Challenges of Identifying Human Trafficking Victims

V. Responding to the challenge

VI. IOM's Counter Trafficking Programs

1. IOM's Counter Trafficking Approach

2. Key Challenges

VII. IOM Best Practice - Fighting Child Trafficking in Ghana

VIII. IOM Best Practice - Study of Victims Trafficked into

the Fishing Industry in the Mekong Subregion

IX. IOM Best Practice - Addressing trafficking for sexual exploitation in Nepal 
"It ought to concern every person, because it's a debasement of our common humanity. It ought to concern every community, because it tears at the social fabric. It ought to concern every business, because it distorts markets. It ought to concern every nation, because it endangers public health and fuels violence and organized crime. I'm talking about the injustice, the outrage, of human trafficking, which must be called by its true name-modern slavery."

"Our fight against human trafficking is one of the great human rights causes of our time..."

--President Barack Obama of United States, September 25, 2012

\section{Human Trafficking - A Global Phenomenon}

Human trafficking is one of the fastest growing global phenomenon around the world, and is considered the second most profitable illicit activity next to drug trafficking and reaps more profit than global arms trade. An accurate scale of human trafficking is difficult to discern; however, an estimation of 27 million people have been trafficked worldwide. Organized criminal groups are earning approximately $\$ 150$ billion USD annually in profits from exploitation of forced labour alone and many of these victims of human trafficking are subjected to severe violations of their human rights. Victims of human trafficking often face rape, torture, debt bondage, unlawful confinement, and threats against their family or other persons close to them as well as other forms of physical, sexual and psychological violence. 


\section{Human Trafficking Statistics}

- \$150 billion USD in profit from forced labour alone

- $2^{\text {nd }}$ most profitable illicit activity next to drug trafficking and more profitable than the arms trade

- 27 million trafficking victims worldwide

- $55 \%$ women \& girls | $45 \%$ men \& boys

- $78 \%$ adults | $26 \%$ children (under 18 )

- Approximately 46,000 victims identified in 2012

\section{Definition of Trafficking in Persons}

Supplementing the United Nations Convention against Transnational Organized Crime (2000), the Protocol to Suppress, Prevent and Punish Trafficking in Persons, Especially Women and Children established in article 3 an agreed international definition of human trafficking. Signed in Palermo, Italy, in December 2000, the Protocol came into force on December $25^{\text {th }}, 2003$.

The Protocol defines the crime of trafficking in persons as a process consisting of three constituent elements: action, means and purpose. The action of trafficking involves the recruitment, transportation, transfer, harboring or receipt of persons, which is perpetrated by means of trafficking threat of or use of force, deception, coercion, abuse of power or position of vulnerability. The purpose of trafficking is always exploitation, which is described as including, "at a minimum, the exploitation of the prostitution of others or other forms of sexual exploitation, forced labor or services, slavery or practices similar to slavery, servitude or the removal of organs"

Should any of the identified means be employed, it will render irrelevant any consent the victim may appear to have given to the intended exploitation Moreover, the recruitment, transportation, transfer, harbouring or receipt of a 
child for the purpose of exploitation shall be considered "trafficking in persons" even if this does not involve any of the means mentioned in the Protocol.

1. "Trafficking in persons" shall mean the recruitment, transportation, transfer, harbouring or receipt of persons, by means of the threat or use of force or other forms of coercion, of abduction, of fraud, of deception, of the abuse of power or of a position of vulnerability or of the giving or receiving of payments or benefits to achieve the consent of a person having control over another person, for the purpose of exploitation. Exploitation shall include, at a minimum, the exploitation of the prostitution of others or other forms of sexual exploitation, forced labour or services, slavery or practices similar to slavery, servitude or the removal of organs;

2. The consent of a victim of trafficking in persons to the intended exploitation set forth in subparagraph (a) of this article shall be irrelevant where any of the means set forth in subparagraph (a) have been used;

3. The recruitment, transportation, transfer, harbouring or receipt of a child for the purpose of exploitation shall be considered "trafficking in persons" even if this does not involve any of the means set forth in subparagraph (a) of this article;

4. "Child" shall mean any person under eighteen years of age.

\section{Types of Human Trafficking or Forms of Exploitation}

Victims of trafficking are exploited in many different ways. In general, however, there are two major forms of exploitation 1) human trafficking for the purpose of sexual exploitation; and 2) human trafficking for the purpose of forced labour. Many victims also suffer both labour and sexual exploitation. 


\section{Human Trafficking for the purpose of sexual exploitation}

Human trafficking for the purpose of sexual exploitation (sex trafficking) affects victims who have been coerced, forced or deceived into prostitution, pornographic filming, forced marriage, and other forms of sexual exploitation. A situation of sexual exploitation is often maintained through the use of debt bondage - a practice similar to slave - where traffickers impose an unconscionable "debt" which victims of trafficking must pay off before they could be freed. Frequently, however, traffickers will increase the debt by charging victims for room and board that they are obligated to accept, fining them for sick days, and otherwise making it impossible for the victim to discharge the debt and be "freed". In cases where someone is pushed or maintained in prostitution, or some other form of sexual exploitation, by means of the threat of or use of force, deception, coercion, abuse of power or position of vulnerability is used to push or maintain someone in prostitution, that person would generally be considered a victim of human trafficking and should be protected in a manner that is consistent with the Protocol, and any applicable domestic laws, as well as other international standards, including the OHCHR's Recommended Principles and Guidelines on Human Rights and Human Trafficking.

\section{Human trafficking for the purpose of labour exploitation}

The ILO's Forced Labour Convention, 1930 (No. 29) defines human trafficking for the purpose of labour exploitation (forced labour or labour trafficking) as: "All work or service which is exacted from any person under the menace of any penalty and for which the said person has not offered himself voluntarily". Simply, forced labour refers to victims who are forced to work by means of physical threats, psychological coercion, abuse of the legal process, or other coercive means. 


\section{Child trafficking: Children as a special case}

The UN Protocol recognizes the special situation of children in Article 3 sub-paragraph (c), which removes the need for "means" to be present to be considered trafficking in persons under the UN Protocol. In other words, because children lack legal competence, it is not necessary that "threat or use of force or other forms of coercion, of abduction, of fraud, of deception . . ." be used to be considered trafficking in persons. For example, if a parent arranges to have their child transported into a situation where they are forced to labour (e.g. begging on the streets), this can be considered trafficking, even if the child is a willing participant and is returned after a period of time. It is important to note, however, that national laws on child labour vary greatly, and may not agree with the standards set in the Protocol.

When a child (under 18 years of age) is induced to perform a commercial sex act, proving force, fraud, or coercion against their pimp is not necessary for the offense to be characterized as human trafficking. There are no exceptions to this rule: no cultural or socioeconomic rationalizations should prevent the rescue of children from sexual servitude.

Commercial Sexual Exploitation of Children: Child prostitution and Child sex tourism

Commercial sexual exploitation of children (CSEC) is one major example of child exploitation that is prevalent in many countries including the Republic of Korea. It is sexual exploitation by an adult of a child or adolescent below the age of 18 years with a transaction that could be exchanged in cash or other in other form of payment, and it may be conducted through more than one party. 
The definition of child prostitution set forth in the Optional Protocol to the Convention on the Rights of the Child on the Sale of Children, Child Prostitution and Child Pornography (OPSC) is the following: "the use of a child in sexual activities for remuneration or any other form of consideration." While this is the conventional definition, the Council of Europe Convention on the Protection of Children against Sexual Exploitation and Sexual Abuse gives a more specific definition: "child prostitution shall mean the fact of using a child for sexual activities where money or any other form of remuneration or consideration is given or promised as payment, regardless of this payment, promise or consideration is made to the child or to a third person."

Child Sex Tourism is defined by ECPAT International (End Child Prostitution, Child Pornography and Trafficking of Children for Sexual Purposes) as "the commercial sexual exploitation of children by men or women who travel from one place to another $\cdots$ and there engage in sexual acts with children, defined as anyone aged under 18." CST is a form of Commercial Sexual Exploitation of Children (CSEC), which "constitutes a form of coercion and violence against, children, and amounts to forced [labour] and a contemporary form of slavery." It is when an adult male or female is traveling to another area/region/country to practice CSEC. Although the exact statistical data is unavailable, due to the secretive nature of CST activities, UNICEF has claimed that as many as 2 million children are victims of child sex tourism, and approximately 1 million children are victims in Southeast Asia alone.

According to Korean Institute of Criminology's Investigating current situation of Child Sex Tourism in Southeast Asia and Establish measure to combat Child Sex Tourism, numerous reports and news articles have named Korean men as one of the main perpetrators of CST in Southeast Asia. Korean men are known to prefer young girls that are 13 to 14 years old with no prior sexual experiences, refuse to use condoms, force the girls to perform unwanted sexual acts such as 
insertion of foreign objects and anal sex, be belligerent and intimidating, and demand the drug usage with the girls. Local and international NGOs and news media, as well as ECPAT and the US State Department have criticized Korean men for being perpetrators of CST in South East Asia.

\section{Causes of Human Trafficking}

While causes of human trafficking differ from case to case and state to state; there are common factors that are driving up the ever-increasing profitability and the number of victims of human trafficking.

\section{Demand \& the profitability of human trafficking}

The demand for cheap labour and sexual services is a principle root cause of human trafficking and these related abuses. The reason behind the increasing numbers of human trafficking is due to the demand for cheap and unprotected or under protected labour. Unlikely many other illicit goods, such as drugs, victims of human trafficking are indispensible, meaning that they could be abused repeatedly for profit after reception. Evidently, private agencies were able to profit over $\$ 150$ billion USD annually through the use of forced labour.

In 2008 TIP Report, the State Department observed that "sex trafficking would not exist without the demand for commercial sex flourishing around the world". The 2013 UNODC report has stated that fifty-eight percent of all trafficking cases were trafficking for the purpose of sexual exploitation and an estimation of 4.5 million victims of sex slavery are in existence at any given time. UNODC has stated that approximately 600,000 to 800,000 people that cross the border as trafficking victims each year, the majority of the victims are women and girls for the purpose of forced prostitution. This is a consistent pattern around the globe and it applies to both developing and developed countries. In the European 
Union, most identified victims of trafficking are sexually exploited. According to a report written by the European Commission, close seventy-five percent of registered victims were trafficked for the purpose of sexual exploitation; this was an increase from seventy percent in 2008.

In recent years, since trafficking for forced labour and labour exploitation has gained attention, there has been a noticeable increase in the number of victims of labour trafficking. IOM's data has shown a proportional increase in the number of victims of forced labour identified by IOM compared with those trafficked for sexual exploitation. In 2011, 53 percent of the cases assisted by IOM involved victims of labour trafficking.

\section{Poverty \& restrictive migration policies}

제I장

제파장

제 III장

Common migration push factors, such as poverty, underdevelopment and lack of equal opportunity contribute to the vulnerability of many aspiring migrants. Migrants, especially migrants that are considered as irregular migrants are vulnerable to exploitation and abuse. While many aspiring migrants risk the comforts of their home to search for opportunities abroad in hopes for a better life, many migrants face difficulty adjusting to their new homes and risk falling as victims of human trafficking. For criminal groups, recruiting and exploiting vulnerable, and irregular, migrants is relatively easy and often carries a low risk of detection, due to migrant's irregular status. Often, these criminal groups are target underdeveloped communities abroad in search vulnerable populations that will fall prey for their deceptive human trafficking operations that promises victims favorable opportunities when in fact it is a human trafficking scheme.

Overly restrictive immigration policies often leave aspirant migrants to have no choice but to remain as irregular migrants, which sustains the vulnerability of migrants to fall into victims of human trafficking. Furthermore, being an irregular 
migrant reduces their opportunity to receive benefits and protection provided by the state. When irregular migrants come forth to report exploitation and abuse of human trafficking from criminal groups, they are often viewed and treated as criminal of illegal immigration rather than protected as victims of human trafficking.

\section{The Challenges of Identifying Human Trafficking Victims}

Identifying victims of human trafficking is a key challenge to the issue. In 2012, only 40,000 victims of human trafficking have been identified, in contrast to the estimated 27 million men, women, and children of victims of trafficking. This means that only a miniscule proportion of victims of human trafficking, who are subjected to exploitation and abuse, have been identified by the states and are receiving the protection and benefits that they need.

Furthermore, victims of trafficking are often misclassified and fail to receive protection services and lose their access to justice. Even worse, when victims are identified as illegal migrants rather than victims of human trafficking they are subjected to further abuse and trauma. This also reinforces traffickers to have a stronger control against the victims because victims are reluctant to seek help due to their fear of incarceration.

Stereotype also affects victim identification. Often governments do not see male victims of labour exploitation as victims because there is a common belief that only women become victims of human trafficking. States must look beneath the surface to fully understand human trafficking issues under their own jurisdiction.

To adequately identity victims of human trafficking, state must do more than just comply with the Protocol and pass anti-trafficking laws that meet international standards. 


\section{Responding to the challenge}

Trafficking in persons is a global problem that affects hundreds of thousands of people every year. Responding to human trafficking is a daunting task for governments, policymakers and organizations that assist victims. What can be done? Comprehensive counter-trafficking activities often focus on three broad objectives:

1. Prevention

2. Protection

3. Prosecution

The complexity of human trafficking requires a holistic, human rights-based response that is both broad enough to address the problem on multiple levels and specific enough to make sense in the local context. Human traffickers look for existing migratory flows and potential migrant groups that can be exploited. While trafficking often involves crossing national borders, there are also significant numbers of victims that are trafficked within their own national borders. Identifying the local context and the specific mechanisms of trafficking that are taking place within a country is essential to creating a strategic response.

Prevention activities are extremely important in combating trafficking. Countries of origin might work to provide alternatives to groups that could be vulnerable to trafficking in persons, for example. A transit country could work on strengthening border control and providing training to officials to enable them to identify sub-groups of trafficked persons within larger migrant groups moving through their country, legally or illegally. Destination countries might look at exploitation taking place within their borders, and work to strengthen the labour rights of migrants, or could work to facilitate legal flows of migrant workers to lessen the demand for irregular migrants. Countries with internal trafficking issues 
might strengthen education or create employment programs in vulnerable communities that provide opportunities.

In addition to activities designed to prevent trafficking in persons, protecting victims is an essential part of any counter-trafficking response. Protection includes providing immediate protection for potential or identified victims of trafficking. It also means keeping identified victims safe while meeting their immediate basic needs (e.g. shelter, medical, psychological and psychosocial care, food and clothing). Following this, interim care and return and reintegration/integration options should be discussed. This includes options for settlement in the destination area, third country or in another part of the victim's home country as appropriate. Keeping victims safe also requires a high level of confidentiality when managing cases - the identity of victims must be protected. This is essential not only to protect victims and service providers from traffickers, but also to protect victims from potential stigma within their families or communities.

Protection also means creating an environment (social, political and legal) that fosters the protection of victims of trafficking. This could mean creating special temporary or permanent visas that allow victims from other countries to remain legally in the country of destination (in some cases in exchange for cooperation with authorities). Appropriate legislation can be used not only to prosecute traffickers, but also to protect victims. Access to the judicial system grants victims the opportunity for justice and compensation. Emphasis must be given to the fact that victims of human trafficking are victims of crime and must be recognized and treated as such - not as criminals themselves.

Protection could also involve helping victims return to their home country or community - safe voluntary return and reintegration/integration. This includes providing an individualized, victim-centered response to help reduce a person's vulnerability to re-trafficking. 
Prosecuting traffickers is another important part of a comprehensive strategy to combat trafficking in persons. Strengthening legislation and policy to hold traffickers accountable for their crimes is necessary in order to have an effect on traffickers. In some countries, the assets of traffickers are confiscated and used to fund victim assistance projects. International cooperation is extremely important, especially when the crime is transnational in nature.

Finally, it is important to keep some crosscutting themes in mind when working in counter-trafficking, such as:

- Victim-centered

- Gendered Response

- Collaboration and Partnership

- Sustainability

제 I장

제I장

제 III장

The most successful strategies are those that address the root causes and vulnerabilities related to trafficking in persons, strengthen the legal framework in place to prosecute traffickers and sensitize relevant actors to ensure that victims are at the center of counter-trafficking activities. Though responding to human trafficking is a daunting task, it is a challenge that the global community must continue to address through increased, improved and sustainable counter-trafficking measures and enhanced cooperation.

\section{IOM's Counter Trafficking Programs}

IOM has been working to counter the trafficking in persons since 1994. In this time, it has implemented more than 800 projects in over 100 countries, and has provided assistance to approximately 20,000 trafficked persons. Its primary aims are to prevent trafficking in persons, and to protect victims from the trade while offering them options of safe and sustainable reintegration and/or return to their home countries. 
IOM operates from the outset that trafficking in persons needs to be approached within the overall context of managing migration. Its broad range of activities is implemented in partnership with governmental institutions, NGOs and international organizations. The approach is based on three principles that govern all its counter-trafficking activities:

- Respect for human rights

- Physical, mental and social well-being of the individual and his or her community

- Sustainability through institutional capacity building of governments and civil society

Building on its individual commitment and global presence, IOM strengthens the capacities of its partners in government and civil society and sets operational standards to achieve sustainable results that will:

- Provide protection and empower trafficked women, men, girls and boys;

- Raise awareness and understanding of the issue; and

- Bring justice to trafficked persons.

\section{IOM's Counter Trafficking Approach}

Trafficking in persons is not an isolated phenomenon. It is inextricably linked to broader international migration dynamics, "including the interests, capacities, and structures of nation states, civil society and international organizations, private companies and criminal groups as well as those of migrants themselves." As the world's leading organization on international migration, IOM approaches human trafficking with a principal emphasis of effectively contributing to protecting and assisting migrants in need, including those who have been trafficked, exploited and abused, in cooperation with its national governments and civil society partners. 


\section{Preventing Trafficking}

Traditional IOM efforts to prevent human trafficking focused on raising awareness among aspirant migrants in countries of origin about the risks of irregular migration and human trafficking. These efforts were rooted in the hope that aspirant migrants, upon learning of the dangers inherent in irregular migration, would either decide to explore legal migration opportunities or refrain from migrating as a means of self-preservation. But whether the desired behaviour change is likely to follow from the dissemination of such messages has always been questioned, especially in contexts where aspirant migrants see few, if any, viable alternatives. Other types of prevention initiatives have since followed, including whistle-blower campaigns to educate the general public about trafficking at destination points while encouraging individuals to report suspected incidents; campaigns to empower migrants with information about how they can protect themselves once they have arrived at their intended destination, and; campaigns to promote a more positive image of migrants and educate the public on the benefits of migration as a means of undermining xenophobia and other anti-social attitudes which allow trafficking to flourish.

IOM also conducts both quantitative and qualitative research as an essential information source to improve its - and others - fight against human trafficking. Specific areas of focus have included human trafficking routes and trends, the causes and consequences of human trafficking both for the individual trafficked person and for society as well as the structures, motivations, and modi operandi of organized criminal groups. While much of this work has been done at national level, IOM increasingly collects and analyzes data on human trafficking from a regional perspective to better support cooperation between states to combat cross-border trade. To support these efforts, IOM carries out considerable research in the areas of legislation and policy. 


\section{Protection through Assistance}

Trafficking in persons is a crime against humanity, and its victims suffer a wide range of human rights abuses. In working for their effective protection, IOM concentrates on programming which restores the rights of trafficked persons and other vulnerable migrants through the provision of humanitarian and other forms of direct assistance.

\section{Rights-based Direct Assistance}

IOM direct assistance projects aim to protect trafficked persons from torture, slavery, and forced and compulsory labour, and so uphold the right to life, as well as the rights to adequate food, and clothing, and housing by establishing and maintaining shelters, together with government and non-governmental partners. In the absence of trafficking-specific shelters, IOM works with its government and non-government partners to identify the most appropriate accommodation available that meets the minimum standards outlined in chapter 4 of the IOM Handbook on Direct Assistance for Victims of Trafficking (2007).

Key among these is the requirement that a beneficiary's participation in a shelter program be on a voluntary basis, and for this reason IOM requires that shelters be open facilities.

IOM also prioritizes medical and psychosocial support so that its beneficiaries enjoy the highest attainable standard of physical and mental health; a key challenge given the trauma experienced by many trafficked persons. IOM's 2009 publication, Caring for Trafficked Persons, outlines the 12 key ethical and human rights standards that are to be integrated into all aspects of health care for trafficked and exploited persons. 
Another feature of IOM programming is the availability of assisted voluntary return (AVR), which is a key tool in helping trafficked persons realize the right of each person to return to his or her country. AVR is also intended to uphold the right to a safe return, and to achieve this AVR programmes include pre-departure, transit, and reception assistance upon arrival, as well as continual risk assessment throughout the entirety of the process. In cases in which the victim is an unaccompanied migrant child, the AVR concept also requires that a family assessment be conducted to ensure that family members were not involved in child trafficking and that they have the interest and means to receive and care for the child. It also explicitly requires that the return be voluntary, and provides pre-return counselling to ensure that trafficked persons and other vulnerable migrants have sufficient information to make an informed decision about whether to return. When working with unaccompanied migrant children, AVR projects also require that: a competent child protection authority has established that return is in the child's best interest, and; that legal guardians are involved both in country of destination and in country of origin.

제 I장 제I장

Integration and reintegration support are essential in promoting the rehabilitation of trafficked persons and other vulnerable migrants and reducing the risks of re-trafficking.

Not only does re/integration support further enable enjoyment of the right to a safe return in cases in which the beneficiary has decided to return, it contributes to upholding a beneficiary's rights to work under just and favourable conditions, the right to an adequate standard of living, and the right to education, as well as restoring his or her right to family life. Furthermore, IOM recognizes the uniqueness of each beneficiary's experience and aims to provide the individually-tailored support required to ensure his or her sustainable well-being. Often this will include support for employment counselling and job placement activities, educational development or vocational training, income 
generating initiatives, family mediation, and/or financial assistance to support family and/or community development.

Many IOM programs include legal support for trafficked persons migrants in countries of destination and/or origin, often as a means of ensuring the respect for a beneficiary's other rights, including additional status-related rights to which victims of trafficking, in particular, are increasingly entitled under regional or national law. In an administrative or criminal context, this generally consists of the provision of information on relevant court proceedings. IOM may also help trafficked persons and exploited migrants realize the right to remedy by ensuring access to legal counsel if the beneficiary intends to pursue a civil claim against, for example, an unscrupulous employer.

All IOM programs adhere to IOM Data Protection Principles and Guidelines to ensure that a beneficiary's privacy rights are upheld throughout the direct assistance process. These require IOM to collect and manage the personal data of its beneficiaries in a manner that is consistent with inter alia the principles of consent and confidentiality throughout the direct assistance process.

\section{Building Capacities to Prevent, Protect, and Prosecute}

IOM also works to build the capacities of other actors, including national governments and civil society organizations, to combat trafficking in persons. A large part of this effort is concentrated on training criminal justice actors, including immigration and border management officials, police officers, and labour inspectors, as well as prosecutors and judges. IOM's global experience in working both with trafficked and exploited migrants, as well as national migration officials, has given it considerable insight into the diversity of challenges faced by front-line law enforcement personnel in particular. 
IOM also regularly contributes to the development of national law and policy on trafficking in persons, including advising on participating in many national referral systems. Equally important is its focus on building cross border partnerships between national law enforcement agencies. With its global presence, IOM supports the organization of bi-lateral and multi-lateral cooperation at political and operational levels, and encourages information sharing across borders.

\section{Key Challenges}

The proper identification of migrants as victims of trafficking remains the most enduring challenge to their effective protection, both for IOM and its government and civil society partners. It is the essential first step to ensuring that the rights of trafficked persons are respected.

제I장

제팡장

제피장 capture information about recruitment tactics, expectations at the time of recruitment, means of transportation, means of control, and exploitation experienced, if any. This individual case data is then uploaded onto IOM's Global Human Trafficking Database. The IOM screening form a comprehensive and well-tested tool that has been adopted and adapted by many governments and non-governmental organizations around the world.

Widespread ratification of the UN Protocol to Prevent, Suppress and Punish Trafficking in Persons, especially Women and Children, has resulted in a significant increase in national legislation which has inter alia served to enhance protection for trafficked persons in many countries. While this is generally a 
positive development, it has also created an increasingly large protection gap between those migrants who are formally identified as victims of trafficking, and other highly vulnerable migrants who have suffered exploitation, extortion, and physical and psychological abuse, particularly those migrants in an irregular situation.

In adhering to the Protocol's definition as the eligibility standard for IOM direct assistance projects, many caseworkers are confronted with a recurring challenge of being unable to address the needs of migrants who had been abused or exploited (or who were highly vulnerable) but who could not be identified as victims of trafficking according to article 3 .

In response to challenges of victim identification, IOM has encouraged a broadening of the eligibility criteria of its direct assistance projects to include 'victims of trafficking, exploitation, and abuse', as well as of those migrants who are considered highly vulnerable to such abuses, such as unaccompanied migrant children.

Known as the 'needs-first approach', this re-focusing evolved from IOM's experience in mixed migration contexts, in which people with varying motivations and reasons for migrating, use the same modes of transport, employ the services of the same smugglers and are exposed to the similar risks and abuses. 'Needs-first' projects include victims of trafficking, but does not require that a migrant be formally identified as such to be eligible for direct assistance through an IOM counter-trafficking project. Instead, IOM caseworkers focus on assessing and addressing the specific needs of individual migrants. In addition to serving a larger group of migrants who need help, the approach also improves IOM's capacity to properly identify victims of trafficking, given that it allows for a prolonged process of direct assistance provision during which trafficking indicators are more likely to be revealed. 


\section{Regional Approach by IOM}

IOM continues to promote dialogue and cooperation on protection of vulnerable migrants and counter-trafficking efforts at a local, national, regional and international level. Such initiatives included facilitating national and regional CT Taskforces, developing inter-institutional victim identification and assistance mechanisms, promoting regional protection initiative in the framework of Regional Consultative Processes (RCPs) and Regional Bodies, and participating in international initiatives and coordination mechanisms, including UNGIFT and Inter-Agency Coordination Group against Trafficking in Persons (ICAT). In 2011, ICAT agreed to jointly develop policy papers on five priority issues at the core of the anti-trafficking debate, focusing effective counter-trafficking efforts and improved approaches.

\section{IOM Best Practice - Fighting Child Trafficking in Ghana}

\section{Child Trafficking in Ghana}

Reports about children forced to work in the fishing industry in Ghana first surfaced in 2001, and a fact finding missing in 2002 confirmed the existence of an extensive network of child trafficking that existed in the fishing industry. The trafficked children were found to be working under exploitative and hazardous conditions in fishing communities along the Volta Lake.

Through in-depth analysis of the findings of the mission, it was discovered that the causes of child trafficking are often related to poverty and broken homes, whereby parents sell their children to fishermen for a number of years in return for money (USD 50 - USD 100). Most often, these children are not returned to their families and are kept under bondage, working in deplorable and dangerous conditions. They are often ill-treated, malnourished, and forced to 
work extremely long hours on the lake without adult supervision. Furthermore, they are usually denied access to education, health care or leisure activities.

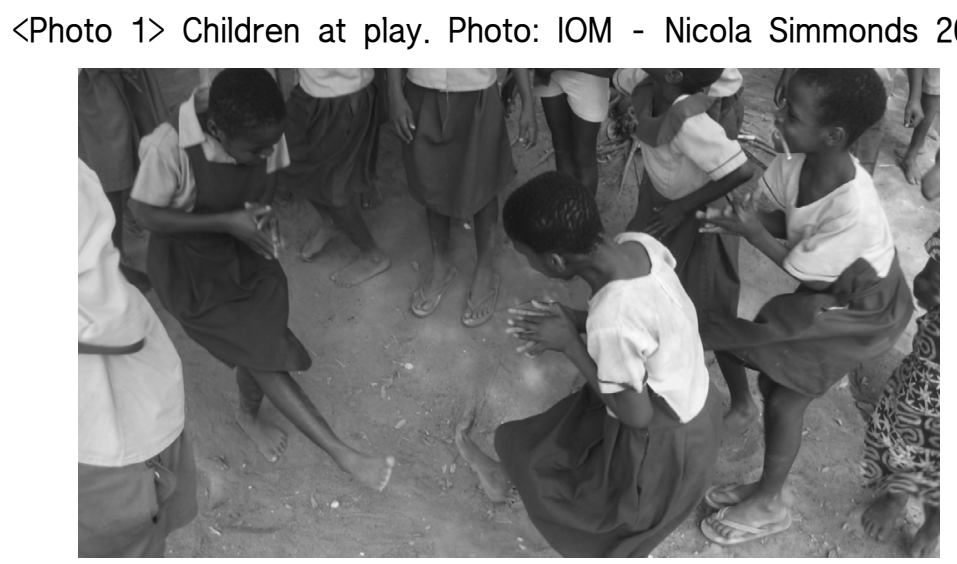

Since December 2002, IOM Ghana has been working with the Government of Ghana, communities and local partners to counter the occurrence of human trafficking within the country. The counter-trafficking team focuses on three key principles: Prevention, Protection, Prosecution (Law Enforcement Trainings), with an additional emphasis on Partnership. The main activities include direct assistance to children, the sensitization of families and fishermen and capacity building of Ghanaian officials. Direct assistance incudes the rescue, rehabilitation, reintegration and long-term monitoring of children who worked as bonded labourers in fishing communities.

\section{Prevention}

One of the most effective ways of ensuring that children do not become victims of trafficking is to prevent it from taking place. In this regard, the public has to be made aware of children's rights and of the legal consequences of abusing these rights. 
- Activities: community outreach, role plays, dramas, film shows, legislation education, community development/micro-grant assistance (kente-weaving, bead-making)

- Outcome: FREE TO BE ME Toolkit; The roll-out of a child protection and child trafficking toolkit in 2013, which aims to promote a community driven approach to preventing trafficking and protecting children.

\section{Protection}

Protecting trafficked children is of paramount importance in combating child trafficking in Ghana. Trafficking is a direct violation of the child's right to grow up in a family environment and develop to his/her potential. In addition, trafficked children face abuses, including violence and sexual exploitation. Thus, it's important to protect children by removing them from the exploitative and abusive situations and return them to their home communities and parents/guardians, giving them the opportunity to grow up in a family environment.

제I장

제파장

제피장

섹

터

- Activities: The 5 Rs, including: I) Research/Registration, II) Rescue/Release, III) Rehabilitation/Recovery, IV) Return/Reunification, and V) Reintegration

- Outcome: To date, more than 731 children have been rescued from the fishing industry. 


\section{The Rescue Process}
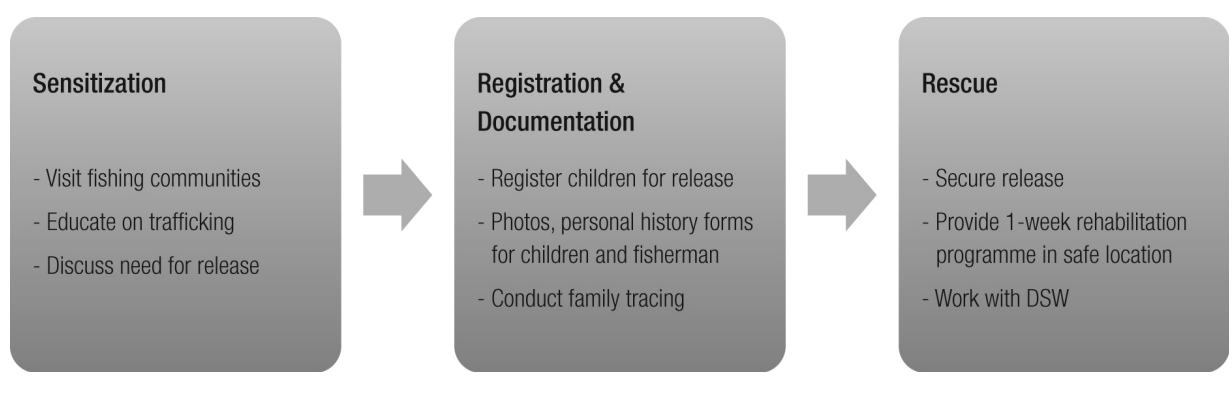

The Rehabilitation Process
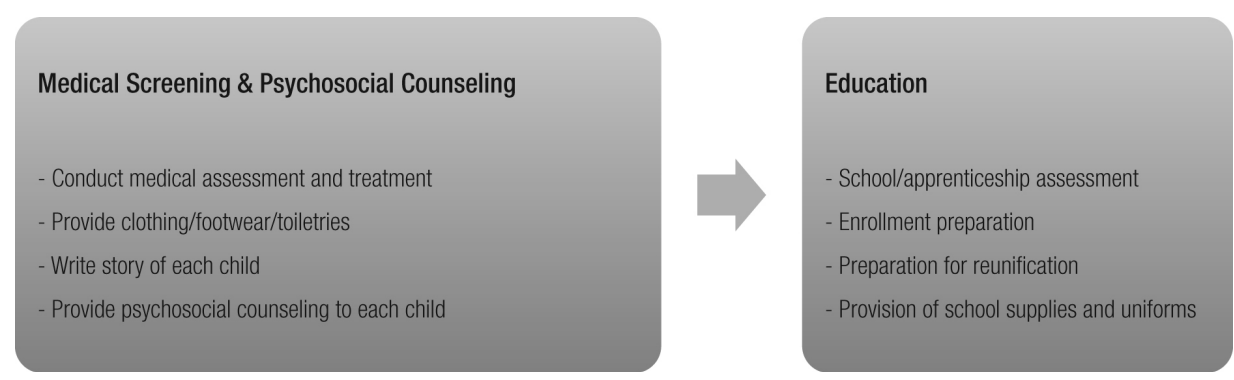

The Reintegration Process
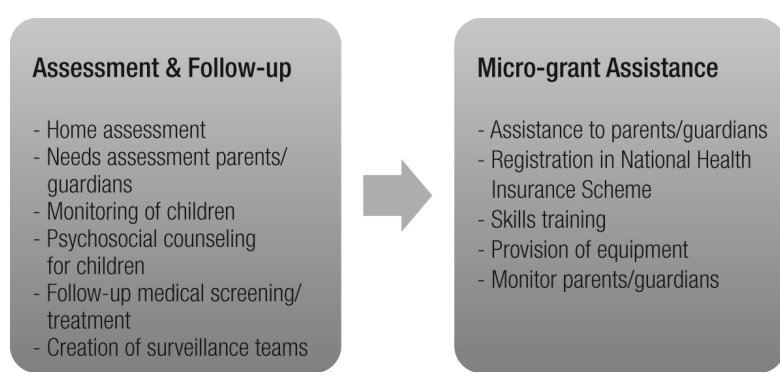
Education
- Assess schools
- Schools or apprenticeship placement
- Provision school supplies
- Monitoring attendance
and performance

\section{Prosecution (Law Enforcement Trainings)}

In 2005, the Government of Ghana passed the Human Trafficking Act, allowing for the prosecution of those who engage in this crime. Thus, in collaboration with relevant government institutions such as the Police Service's Anti-Human Trafficking Unit, the Immigration Service and the Ministry of Women and 
Children's Affairs, IOM Ghana initiated capacity building activities. These aim to strengthen the capacity of Ghanaian law enforcement agencies and judicial institutions to detect, investigate, prosecute, and convict traffickers.

- Activities: workshops/trainings, provision of equipment, evaluation of investigation and prosecution progress, annual meetings

- Outcome: 170 law enforcement officials and 25 Parliamentarians trained on the Human Trafficking Act.

\section{Stakeholders and Partners}

To implement counter-trafficking activities, IOM collaborates with a wide range of stakeholders and partners including government agencies such as the Ministry of Women and Children's Affairs, the Department of Social Welfare, and the Anti-Human Trafficking Unit of the Ghana Police Service. IOM also collaborates with NGOs in intervention areas such as rescue, reintegration and prevention activities as well as civil society organizations and community members, especially chiefs, traditional elders, opinion leaders and teachers.

VIII. IOM Best Practice - Study of Victims Trafficked into the Fishing Industry in the Mekong Sub-region

The IOM Report Trafficking of Fishermen in Thailand, highlights the severe maltreatment, abuse and trafficking of men into the Thai fishing industry. According to the study the industry is characterized by informal recruiting processes, involving sub-contractors, intermediaries and lack of transparency regarding wages and conditions of work, all of which foster abuse and human trafficking. 
Trafficked men often do receive written contracts, leading them to believe that the job offers are legitimate and the agreed conditions will be upheld. In many cases, the recruited men pay a "broker's fee" of several hundred or more dollars to an agent, who arranges travel, transit visas and/or false documentation. The exploitation of men is often related to shortfalls in supply in host countries (60,000 fishermen are seasonally needed in Thailand) and again is symptomatic of gaps in trafficking and labor migration laws and policy in the GMS.

These men represent a larger trend in the fishing industry in Southeast Asia and worldwide with more and more reports surfacing on the prevalence of human trafficking for purposes of labor exploitation on fishing vessels in all major regions of the world.

In fact, IOM has been involved in assisting trafficked fishermen from Myanmar, Vietnam, and Ukraine. Despite some variations in the modus operandi of traffickers, victims have faced similar experiences. Unfortunately, to date most traffickers have gone unpunished and victims are not compensated.

A good example for data collection and regional research, the Study on Trafficking, Exploitation and Abuse in the Mekong Sub-region (STEAM) aims to enhance the care and support to trafficked persons in the GMS, through the improvement of policies and health services based on the evidence of trafficked persons' physical and mental health consequences and associated health care needs identified in the research. Research is being conducted in Thailand, Vietnam and Cambodia.

In Cambodia, field work interviews with trafficked victims started in October 2011. To date STEAM has captured 184 first and 75 follow up interviews with identified victims of trafficking and exploitation in Cambodia. 
The majority of victims interviewed by STEAM in Cambodia are fishermen which accounted for $87 \%$ of all victims. These men migrated irregularly to Thailand via informal recruiter and/or broker with the promise of paid work but many ended up in horrific situations of abuse and exploitation. Fishermen have been assisted and retuned home by IOM from Indonesia, Malaysia, Mauritius, Fiji, South Africa, Timor Leste, and Senegal.

Most of the Cambodian victims interviewed are from the rural areas and the reasons behind their migration were reported as limited income generating opportunities at home, general poverty, and other socio-economic factors such as lack of education, and skills no or limited land for farming and the absence of capital to invest in their own livelihoods.

IX. IOM Best Practice - Addressing trafficking for sexual exploitation in Nepal

<Photo 2> Survivors of human trafficking in a skills development training.

Photo: IOM 2012

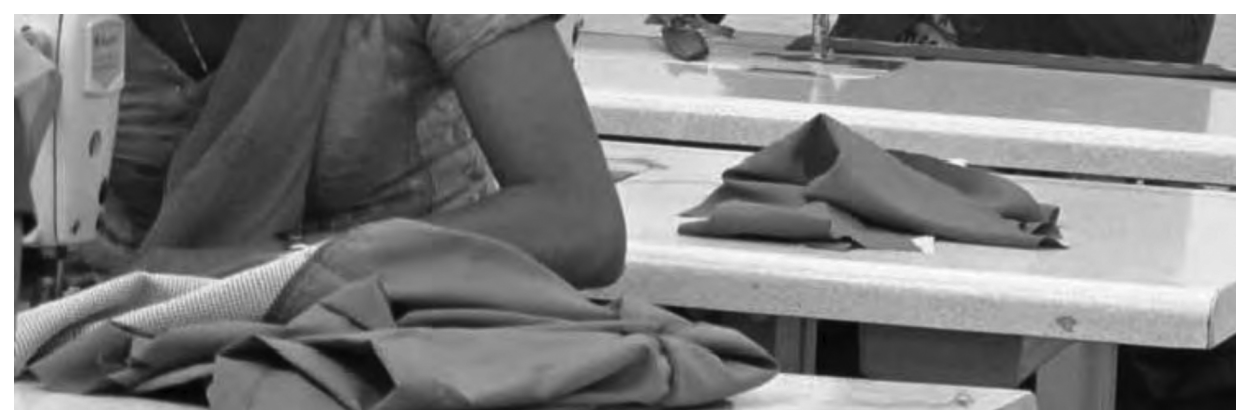

The trafficking of Nepalese women, to India in particular, and other parts of Asia for various purposes has increased considerably over the last decades. Nepal is a country of origin for trafficking in persons especially for the purposes of labor, sexual, illicit organ transplantation and other forms of exploitation. 
Although the scope of human trafficking in Nepal is difficult to quantify due to a lack of reliable statistical information, Nepal's open and porous borders with India and the hidden nature of the crime make trafficking problematic to accurately identify and address effectively.

IOM Nepal has been providing sustainable sources of livelihood to survivors of trafficking by creating income generating opportunities through a multi-stake holder engagement under the Trafficking Risk Reduction in Nepal (TRRIN) project. Under this approach, the private sector extends franchise, creates market linkages and provides skills development training and job placements to the project participants as a part of their desire to promote Corporate Social Responsibility (CSR). The Government of Nepal extends necessary legal and infrastructure support for establishment of small businesses. Local NGOs provide mentoring support to the participants until they are capable and confident to manage the businesses by themselves.

Parbati (name changed) and her family (grandfather, parents, brother and four sisters), grew seasonal crops for a living. Parbati's grandfather used to make Doko (used for carrying goods mostly in hill regions) from bamboo, her brother and sisters were studying at the local school and her mother had migrated to Kuwait for overseas employment. In order to support her family, Parbati was sent to a family in the capital Kathmandu to work as a domestic worker at a very young age. One day, after Parbati returned to her employer's house from a visit home, she found the household in Kathmandu deserted. She was 11 years old at that time. A stranger came up to her and offered to take her to her employer. However, Parbati was tricked into leaving her employer's house in Kathmandu and then trafficked to Mumbai, India, where she was handed over to a brothel owner. The brothel owner forced her into prostitution for one and a half years. During this time Parbati was also forced to take drugs. It was only after a raid by the Mumbai Police, that Parbati was identified and rescued and 
taken to a NGO shelter where she stayed for almost 2 years. During her stay, she took sewing training classes in order to develop her skills and to be able to support herself. On the initiative of Shakti Samuha, a Nepali NGO working with trafficking victims - and a partner organization of $\mathrm{IOM}$ - Parbati was returned to Nepal. Parbati is currently staying at an NGO shelter and is applying her skills through the TRINN project. During her stay in India, Parbati had the opportunity to share her problems and concerns with other victims from Indian and Bangladesh. Most of them had been trafficked with false promises of love or better employment opportunities. Many of them were brutally abused when they tried to flee from their exploiters. Parbati advises "Women should learn more and should gain practical knowledge. Women should listen to their parents and if someone tries to lure a woman with employment opportunities abroad, she should inform her family," Parbati adds "it is not easy to make a living in other countries so one should not be tricked by false promises."

To date, IOM has supported in economic rehabilitation of more than 200 victims and potential victims of trafficking though enterprise setup and skills development trainings followed by job placement opportunities in Nepal. 


\section{Bibliography}

Council of Europe. "Council of Europe Convention on the Protection of Children against Sexual Exploitation and Sexual Abuse." Council of Europe. Web. 07 August 2014.

ECPAT. Global Monitoring Report on the Status of Action Against Commercial Sexual Exploitation of Children. Thailand: ECPAT, 2011. Web.

End Child Prostitution, Child Pornography and Trafficking of Children for Sexual Purposes. Global Monitoring Report on the Status of Action Against Commercial Sexual Exploitation of Children. Thailand: ECPAT, 2011. Web.

European Commission. The EU Strategy towards the Eradication of Trafficking in Human Beings 2012-2016. Brussels: European Commission, 2012. Web.

Institute for Gender Research SNU. 2010 성매매 실태조사 (2010 Situation Report on Prostitution). Seoul: MoGEF, 2010. Web.

International Labour Office. "Commercial sexual exploitation of children”. International Labour Office. Web. 07 Aug 2014.

International Labour Office. Profits and Poverty: The Economics of Forced Labour. Geneva: International Labour Office, 2014: Web.

International Labour Office. The Cost of Coercion. Global Report under the follow-up to the ILO Declaration on Fundamental Principles and Rights at Work. 2009

International Organization for Migration. handbook on performance Indicators counter-trafficking projects. Geneva: International Organization for Migration, 2008. Print

International Organization for Migration. IOM Case Data Global Figures \& Trends Human Trafficking. 2011 
Korean Institute of Criminology. Investigating current situation of Child Sex Tourism (CST) in Southeast Asia and Establish measures to Combat Child Sex Tourism. Seoul: Korean Institute of Criminology, 2012. Print.

United Nations. "Optional Protocol to the Convention on the Rights of the Child on the Sale of Children, Child Prostitution and Child Pornography." United Nations Treaty Collection, 06 Aug 2014. Web. 07 Aug 2014.

United Nations Office on Drugs and Crime. Global Report on Trafficking in Persons 2012. New York: United Nations, 2012. Web.

UNICEF. Child protection from violence, exploitation and abuse. September 2010.

http://www. unicef.org/protection/index.html

U.S. Department of State. Trafficking in Persons Report June 2013. Washington: U.S. Department of State Publication, 2013. Web.

U.S. Department of State. Trafficking in Persons Report June 2008. Washington: U.S. Department of State Publication, 2008. Web.

“큐리오스, 영화로 아동 성매매, 포르노, 성폭력 근절캠페인” (Curios, campaigning against child prostitution, pornography, and sexual violence with films), Christian Today, 11 April. 2013. 